\title{
Effects of language policy in the school on the learning of Kiswahili in Kapseret Division, Uasin Gishu County, Kenya
}

\author{
Rebecca Wanjiku-Omollo \\ University of Eldoret, Kenya
}

\begin{abstract}
Kiswahili is an official and a national language in Kenya, It plays a major communicative role in Kenya but there have been complaints about the poor academic performance both at primary and secondary school levels. This paper is a report of a study that was carried out in 2012 in Kapseret Division of Uasin Gishu County. It established the effects of language policy in schools on the learning of Kiswahili. It was guided by sociocultural theory (SCT) and was descriptive in nature. Simple random sampling was used to select 15 out of 50 schools, it was also used to select $20 \%(N=750)$ of standard six pupils from the selected schools. Purposive sampling was used to select 30 upper primary Kiswahili teachers ; one class six Kiswahili teacher and a Kiswahili panel head. Data was collected using questionnaires and observation checklists. It was analyzed using descriptive statistical techniques such as percentages and frequencies. The research found out that Kiswahili language was rarely used as a medium of communication in school. However, teachers motivated the learners by congratulating them for doing well in it.
\end{abstract}

Key Words: Language policy, School environment

\section{Introduction}

Language policy in Kenya has kept on changing in our educational institutions from the period before independence and up to the period after independence. Nabea (2009) states that, the colonial language policy in Kenya is important, putting into consideration the fact that it impacted greatly on post-colonial language policy. Ogechi and Bosire-Ogechi (2002) stated that, barely a quarter of Kenyan population can adequately use English; that remains the advantaged official language and the medium of instruction in the education system, unlike Kiswahili, the co-official language. However, while the leadership appears comfortable with this linguistic situation and would wish to have the status quo maintained, the linguistic situation among lay Kenyans, demonstrate that not all is well on the ground.

Mazrui and Mazrui (1998) states that, in the first epoch of colonial language policy, there were several players involved in the formulation of language policy. Among these were Christian missionaries who thought that the gospel would best be spread in mother tongue. The colonial administrators controlled teaching of English to Africans in order to obtain low cadre employees in their administration. There were also the British settlers who feared the Europeanization of Africans through English language lest they became too educated to accept the role of wage laborers. The interests of all these players were always vacillating and inchoate, impacting language policy.

During the United Missionary Conference in Kenya in 1909, the language issue; mother tongue, Kiswahili and English in the realm of education was discussed. The Conference adopted the use of mother tongue in the first three classes in primary school, Kiswahili in two of the middle classes in primary, while English was used in the rest of the classes up to university (Gorman, 1974).

At times the administrators favored the promotion of either African languages or English in view of their interests at stake, for example, 1924 Phelps-Stokes Commission recommended that Kiswahili be dropped in the education curriculum, except in areas where it was the first language. The colonial language policy in Kenya prior to World War II was never compact, and its position as regards the teaching of English and African languages was mainly ambivalent.

Beecher's Report 1949, Binn's Report 1952 and Drogheda Commission of 1952 recommended that English be introduced in lower primary and taught alongside the recommended mother tongue in early primary classes, while English to be taught from upper primary to university. From the foregoing, it is apparent that Kiswahili was dropped except in areas where it was the mother tongue. Implementation of this policy took effect in 1953-1955 (Gorman, 1974). Kiswahili elimination from the curriculum was partly aimed at forestalling its growth and spread, on which Kenyans freedom struggle was coalescing (Mazrui \& Mazrui, 1998).

Prator-Hutasoit Commission further boosted English at the expense of local languages by endorsing English as the only language of instruction in all school grades, heralding the New Primary Approach, better known as the English Medium Approach to implement the new curriculum. Teachers were to be trained in English while their mother tongue was viewed as a premium in teaching the lower primary schools additionally, 
New Primary Approach was introduced in urban schools and their neighboring Teacher Training Colleges (Mukuria 1995).

In 1964, Kenya Education Commission mounted a survey to establish the interests of citizens with regard to language use. The findings revealed that most people wanted a trilingual approach to education (Nabea, 2009). Mother tongue was preferred for verbal communication especially in rural areas, while English and Kiswahili were preferred for education from lower primary to university. Kiswahili was favored in education for purposes of national and regional unity. It was the appropriate language for Pan-African dream (Mazrui \& Mazrui, 1996).

Kiswahili unlike English, was not anchored in the school curriculum, and for a long time, it remained an optional subject. Many Kenyans were in favor of English as the medium of instruction from the first class in primary school to university. More so the commission threw its weight behind English language arguing that it would expedite learning in all subjects by ensuring smooth transition from 'vernaculars,' and owning to its intrinsic resources (Ominde, 1964).

Gachathi Report (1976) recommended the use of English for instruction from class four in primary to University. The commission also declared Kiswahili an important subject in primary and secondary classes, though the language received inferior status as compared to English in the curriculum. English was allotted 810 periods out of 40 per week, while Kiswahili was allotted 3 hours (Chimerah, 1998). Njoroge (1991) states that, in 1981, Mackay Commission allowed English to remain the language of instruction, while Kiswahili was made a compulsory subject in both primary and secondary education. The Commission further advised that mother tongue be used in lower grades of primary schools, in areas where this was possible.

On the face value, the teaching of English in the Kenyan education system was an advantage in the sense that the medium was already a worldwide language that facilitated communication with the outside world. However, its teaching to the Kenyan pupils was also at a cost. In some schools, especially in rural Kenya, mother tongue was forbidden, except in the first three classes of primary schooling, in special cases (Ngugi 1986). This is relevant to the study since forbidding pupils from using their mother tongue meant that Kiswahili was also forbidden since it is the mother tongue of people in the Kenyan coast.

Ogola (2003) states that, the sociolinguistic situation in Kenya is triglossic in the following order: English is top as the official language; Kiswahili in the middle as the co-official language and the local lingua franca. This is relevant to the current research in that although in the current constitution of Kenya, Kiswahili is ranked as an official language, it does not enjoy the prestige that English enjoys.

Language of instruction or the language in which education is principally conducted, is one of the most far-reaching and significant features of any education system. The language of instruction, the language of educational formation, in any society is also the language of hegemony and power (Prah 2003). It is the language in which basic skills and knowledge are imparted to the population, and the medium in which the production and the reproduction of knowledge is taught. It is in this medium that knowledge is accumulated and deposited (Prah, 2003).

If the language of instruction is the same as mother tongue at home, it doesn't only affirm the developmental capacity of mother tongue to grow as a language of culture, science and technology, but also gives confidence to a people, with respect to their historical and cultural baggage (Prah, 2003). This is relevant to the study in that in Kenya and Tanzania in particular, Kiswahili is accepted by people from different ethnic groups and is actually a mother tongue to many young people in the major urban areas in these countries (Mathooko, 2009). It can be used in both urban and rural areas as the Language of instruction leading to. development of the language as well as assist in educational formation.

In conclusion, language policy of the school differs, due to the geographical location of the schools. A school that is peri-urban will use Kiswahili in class one to three, since the area has Kenyans from different ethnic communities, while the school in the rural area learners are taught in mother tongue from class one to three, then from class four English is introduced. This forms a basis of this research, on the effects of language policies on the learning of Kiswahili.

\section{Theoretical Frame Work}

This study was based on the Social Cultural theory (SCT) and the process of second language acquisition by Vygotsky (1987). Firstly, the theory has it that the human mind is always and everywhere mediated primarily by linguistically based communication and secondly, mental functioning is mediated (activity theory). Second language acquisition (SLA) as a mediated process has been viewed in three general perspectives: social mediation by experts and peers, self mediation and the artifact mediation. This research investigated social mediation by experts and peers who play a major role in the learning of Kiswahili language. 


\section{Research Methodology}

A descriptive survey research design was adopted. The study was carried out in Kapseret Division, because of the dismal performance in Kiswahili displayed in K.C.P.E results.

Simple random sampling was used to obtain $30 \%$ of $50(\mathrm{~N}=15)$ primary schools. Purposive sampling was used to select; one class six Kiswahili teachers and a Kiswahili panel head from selected schools. A total of 30 teachers participated in the study. Simple random sampling was used to select $20 \%$ of $750(\mathrm{~N}=150)$ class six pupils schools making a total sample of 180 respondents.

Data collection instruments were observation schedule and questionnaires administered to teachers and learners. Content validity of the instrument was determined by discussing the items in the instrument with the two supervisors from Moi University. Pilot study was done and 0.73 coefficient of reliability obtained. Data analysis was done basing on descriptive statistical techniques such as; frequencies, and percentages.

\section{Results}

The following are the findings of influence of language policy in schools on academic performance of learners in Kiswahili. Teachers' responses concerning this variable were; $86.7 \%(\mathrm{~N}=26)$ stated that Kiswahili language was used once a week as a medium of communication in school. $10 \%(\mathrm{~N}=3)$ stated that it was used twice a week while $3.3 \%(\mathrm{~N}=1)$ was used all days of the week. This implies that different schools had different language policies that guided when to use Kiswahili. It was not the medium of communication and learners were not allowed to use it unless the stipulated day

Teachers were further required to give responses on whether they used Kiswahili language during Kiswahili lessons, whether they address learners in Kiswahili language during Kiswahili lessons and during assembly and whether they motivated their learners to speak Kiswahili. 3.3\% $(\mathrm{N}=1)$ and $43.3 \%(\mathrm{~N}=13)$ strongly disagree and disagree respectively that teachers use Kiswahili language only during Kiswahili lesson. While $50 \%(\mathrm{~N}=15)$ and $3.3 \%(\mathrm{~N}=1)$ agreed and strongly agree respectively that they used Kiswahili language only in teaching of Kiswahili as a subject.

$50 \%(\mathrm{~N}=15)$ disagreed that teachers address learners in Kiswahili during assembly, $6.7 \%(\mathrm{~N}=2)$ were undecided while $30 \%(\mathrm{~N}=9)$ and $13.3 \%(\mathrm{~N}=4)$ respectively agree and strongly agree that they use Kiswahili language to address learners during assembly. $46.7 \%(\mathrm{~N}=14)$ disagreed that they reward learners who do well in Kiswahili while $35.7 \%(\mathrm{~N}=11)$ and $16.7 \%(\mathrm{~N}=5)$ respectively agree and strongly agreed that they reward learners.

This is an indicator that only slightly more than half of teachers use Kiswahili only in the process of teaching while the rest mix the language while teaching. The learner is likely to be affected by this for they are going to imitate the language of the teacher and will end up not being fluent. Additionally the writing of Kiswahili will be affected; the learner may end up using other languages like 'sheng' together with Kiswahili in the process of writing. When teachers use Kiswahili language during the lesson and when addressing the learners during assembly, it creates motivation in the learning process. Additionally, they act as a role model for +learners who would want to speak good Kiswahili. More so, it has been established by research that learners are motivated by their teachers to speak Kiswahili.

Motivation is a very important factor as far as performance is concerned. One of its functions is to energize the behavior of the organisms and arouse it for action. The energy is supplied in proportion to the amount of energy output for a task; motives help to sustain interests and behavior (Ingule etal, 1996).

Learners were also asked to state their opinion regarding language policies in schools and their effect on performance in Kiswahili. $2.7 \%(\mathrm{~N}=4)$ and $36 \%(\mathrm{~N}=54)$ strongly disagreed and disagreed respectively that they are punished for speaking Kiswahili, $58 \%(\mathrm{~N}=87)$ and $3.3 \%(\mathrm{~N}=5)$ agreed and strongly agreed that they are punished for speaking Kiswahili while in school. This implies that in most of the schools teachers prefer other languages at the expense of Kiswahili which is also a national and official language in Kenya.

Punishing learners impacts positively or negatively. The Learning-Based theory of motivation emphasizes on the importance of past experiences to explain the cause of present behavior, that is, human beings are motivated to do those things that brought them pleasant consequences in the past and avoid those that result in negative consequences (Ingule, etal, 1996). Punishing brings negative consequences as a result, the learners are less likely to practice or use Kiswahili because of fear of the end result of using it in school.

$38 \%(\mathrm{~N}=57)$ disagree that Kiswahili is not given priority in school as English, 2\% ( $=3)$ were undecided while $53.3 \%(\mathrm{~N}=80)$ and $6.7 \%(\mathrm{~N}=10)$ agreed and strongly agreed respectively that Kiswahili is not given priority in school as English. Additionally, 1.3\% (N=2), 36.7\% ( $=55), 3.3 \%(\mathrm{~N}=5), 56.7 \%(\mathrm{~N}=85), 2 \%$ $(\mathrm{N}=3)$ strongly disagreed, disagreed, undecided, agreed and strongly agreed respectively that teachers mixed languages while addressing. This is similar observation made during a morning assembly session on a Wednesday $26^{\text {th }}$ October2010. The day was 'Kiswahili speaking day' therefore learners and teachers were encouraged to use Kiswahili language. The following is a sample of the conversation. 
Teacher: Hamjambo wanafunzi?(How are you pupils)

Pupils: (Answer in chorus) Hatujambo mwalimu.(We are fine teacher)

Teacher: Leo ni siku nzuri ambayo wanafunzi wote wamejikakamua kuingia shuleni mapema.Ningependa kusisitiza kuwa ni sharti kila mmoja wenu afuate kanuni za shule. I mean school rules.

(Today is a wonderful day that pupils have arrived at school early. I would want to insist that everyone must follow the school rules).

Hakikisha kuwa hakuna kelele darasani pia uwe msafi kwani

Cleanlines is next to Godliness. Muwe na siku njema.(ensure that noise making is not there in class and be clean because cleanliness is next to Godliness). Have a a nice day.

Pupils: (Answer in chorus) Asante (thank you)

Although the teacher had communicated he broke the school rule of using Kiswahili. He was not a role model and was not motivating the learner to use proper Kiswahili in communication. There was no punishment for those using English on such a day. This treatment of Kiswahili as an inferior language is detrimental, it contributes to poor performance in Kiswahili. The learners mixed the Kiswahili and English in their conversation and also in their writing of insha (composition).

On frequency of Kiswahili language as a medium of communication in the school, 51.3\% ( $\mathrm{N}=77)$ of learners stated that Kiswahili was used once a week. $35.3 \%(\mathrm{~N}=53)$ stated that it was used twice a week with $13.3 \%(\mathrm{~N}=20)$ stating that it was used all the days of the week.

\section{Use of Kiswahili in Debate}

Teachers were asked to state whether there was a debate club in their school and the utilization of Kiswahili as a medium of communication during the debate. $73.3 \%(\mathrm{~N}=22)$ agreed, while $26.7 \%(\mathrm{~N}=7)$ disagreed. 53.3\% ( $\mathrm{N}=16)$ stated that they held debate in Kiswahili once a week, $33.3 \%(\mathrm{~N}=10)$ once per month and $13.3 \%(\mathrm{~N}=4)$ once per term.

Learners' responses on the use of Kiswahili in debate were; $64.7 \%(\mathrm{~N}=97)$ had debate in Kiswahili once per week, $10.7 \%(\mathrm{~N}=16)$ had no debate. Kiswahili Learning needs frequent use of the language, the more involvement in learning activities such as presentation of topics in public, asking and answering questions, the more the learner learns (Vygotysky, 1987). When the learner participates in the debate he gets time to practice different vocabularies, different sentence structures since as he expresses himself he chooses the appropriate words. Additionally it is during such activities that peer mediation takes place. The learners are able to learn from each other and correct one another.

\subsubsection{Use of Kiswahili during Inter-school Competition}

Teachers responses on conducting inter-school quizes and whether they used Kiswahili in such competitions were, $63.3 \%(\mathrm{~N}=19)$ did not conduct interschool competition, 36.7\% ( $\mathrm{N}=11)$ conducted interschool competition. However $43.3 \%$ (13) stated that they had Kiswahili questions during the interschool competition while $56.7 \%(\mathrm{~N}=17)$ stated that there were no Kiswahili questions. The study further established that majority of the learners did not participate in Kiswahili interschool quizes.

Inter school quizes involves learners from different schools who gather together for the purpose of learning. This implies that most schools do not participate in the inter-school quiz. This affected the learning of Kiswahili since he learners do not exercise what they have been taught. Vygotsky (1987) states that, mediation is done by the teachers and learners themselves through dialogue and correcting learners in sentence construction, reading and writing.

\section{Summary}

The inquiry found that Kiswahili language was rarely used in school by both teachers and pupils as a medium of communication. However, majority of the teachers motivated the learners to speak Kiswahili by congratulating them for doing well in it.

\section{Conclusions}

Minimal use of Kiswahili in communication at school affected the learning of Kiswahili. If the learner practices by speaking the language in debate or inter-school competition, he or she will learn the language and viceversa. 


\section{Recommendations}

Schools should come up with clear and working language policies in order to promote the use of Kiswahili language. For example, all the teachers, workers and pupils should use Kiswahili when addressing each other; learners shouldn't be punished for using Kiswahili.

\section{References}

[1]. Chimera, R. (2000). Kiswahili Past Present and Future Horizon. Nairobi: Nairobi University Press.

[2]. Republic of Kenya (ROK).1963. Education at Independence (The Ominde Commission Report). Nairobi: Government Printers.

[3]. (1976). Report of the National Committee on Educational Objectives and policies (Gachathi Report). Nairobi: Government Printers.

[4]. (1988). Report of the Presidential Working Party On Education And Man Power Training For The Next Decade And Beyond (Kamunge

[5]. Report). Nairobi: Government Printers.

[6]. (1999). Totally Integrated Education And Training (TIQET).

[7]. Report Of The Commission Of Inquiry Into The Education System Of Kenya.

[8]. Nairobi: Government Printers.

[9]. Gorman, T. P. (1974). "The Development of Language Policy in Kenya with Particular Reference to Education System:" In Whiteley, W.H. (Ed.) Language in Kenya. Nairobi: Oxford University Press.

[10]. Ingule, F., Rono, R. and Ndambuki P. (1996). Introduction to Educational Psychology.

[11]. Nairobi: East African Educational Publishers.

[12]. Lantolf, J. P. (2002). "Sociocultural Theory and Second Language Acquisition" in Kaplan R.B. (ed) The Oxford Handbook of Applied Linguistics. Oxford University Press. pp 104-114.

[13]. Mathooko, M. (2009). "Actualizing free primary education in Kenya for sustainable Development." In The Journal of Pan African Studies, vol.2, no.8.

[14]. Mazrui, A. A. \& Mazrui, A. M (1998). The Power of Babel. Language and Governance in the African Experience. Nairobi: Oxford E.A.E.P

[15]. Mazrui, A. A. \& Mazrui, A. M (1996). “A tale of two Englishes: The imperial language in the post-colonial Kenya and Uganda. In: Fishman, J. Conrad, A. \& Lopez, A.L. (eds.) Post Imperial English. Berlin: Mouton de Gruyter, 271-302.

[16]. Mukuria, D.M. (1995). “Kenya's Language Policy with Special Emphasis on Kiswahili”in Senamu K. and Williams D. (eds). Creative Use of Language in Kenya. Nairobi: Jomo Kenyatta Foundation, pp.34-44.

[17]. Nabea, W. (2009). Language Policy in Kenya: Negotiation with Hegemony. The journal of Pan African Studies, vol.3, no.1, September 2009.

[18]. Ngugi, T. (1986). Decolonising the Mind. Politics of Language in African Literature. London: Westerly.

[19]. Njoroge, K. (1991). "Multilingualism and Some of its Implications for Language Policy and Practices in Kenya." In Legere, K. (ed.) The Role of Language in Literacy Programmes with Special Reference to Kiswahili (249-269). Bonn: German Foundation for International Development (DSE).

[20]. Ogechi, N. and Bosire-Ogechi, E. (2002). "Educational Publishing in African Languages, With a Focus on Swahili in Kenya." In Nordic Journal of African Studies II (2): 167-184.

[21]. Prah, K. K. (2003). "Going Native: Language and Instruction for Education, Development and Emancipation," in Language of Instruction in Tanzania and South Africa (LOITASA). Mauritius: Book Printing Services Ltd. printers. 